\title{
Research on the Thermal Aging Behaviors of LDPE/TiO 2 Nanocomposites
}

\author{
Jun Liu, Youyuan Wang, Kun Xiao, and Zhanxi Zhang \\ State Key Laboratory of Power Transmission Equipment \& System Security and New Technology, \\ Chongqing University, Chongqing 400044, China
}

Correspondence should be addressed to Kun Xiao; 20104427@cqu.edu.cn

Received 16 February 2017; Accepted 8 May 2017; Published 14 June 2017

Academic Editor: Jim Low

Copyright (C) 2017 Jun Liu et al. This is an open access article distributed under the Creative Commons Attribution License, which permits unrestricted use, distribution, and reproduction in any medium, provided the original work is properly cited.

The ability of antithermal aging of $\mathrm{LDPE} / \mathrm{TiO}_{2}$ nanocomposites was investigated through SEM, FTIR, DSC, and dielectric properties in this paper. The results of SEM images showed that the thermal aging had a significant influence on the structure of Pure-LDPE and $\mathrm{LDPE} / \mathrm{TiO}_{2}$ samples. The measurement of FTIR showed that the content of hydroxyl and carboxyl increased with thermal aging, but the time of emerging aging characteristic peaks for the $\mathrm{LDPE} / \mathrm{TiO}_{2}$ samples was delayed. The DSC measurement indicated that filling $\mathrm{TiO}_{2}$ nanoparticles changed the crystallization behavior of LDPE, played a role of heterogeneous nucleation during the process of recrystallization, and improved the crystallinity of $\mathrm{LDPE} / \mathrm{TiO}_{2}$. Similarly, the aged $\mathrm{LDPE} / \mathrm{TiO}{ }_{2}$ samples had lower permittivity and dissipation factor compared to the aged Pure-LDPE samples. All the results had indicated the $\mathrm{LDPE} / \mathrm{TiO}{ }_{2}$ samples had the significant ability of antithermal aging, especially the $\mathrm{LDPE} / \mathrm{TiO}_{2}-0.5$ samples with good dispersion of nanoparticles. A new model was proposed to illustrate the antithermal aging behaviors of $\mathrm{LDPE} / \mathrm{TiO}_{2}$ samples, which shows that the $\mathrm{TiO}_{2}$ nanoparticles play a role of "crosslinking points" between LDPE molecular chains, increasing the density of crystal structure and reducing oxygen diffusion into materials to break molecular structure.

\section{Introduction}

Polyethylene has been widely used as the insulation material of high voltage cables because of its outstanding physical, chemical, and electrical properties. In addition, the mechanical and electrical properties of polyethylene such as tensile strength, resistivity, permittivity and dielectric loss, breakdown strength, and space charge behaviors can be enhanced by adding inorganic nanoparticles due to its small size and surface effect; the polyethylene/inorganic nanoparticles nanocomposites are regarded as a promising candidate for high voltage direct current cables in the future [1-3].

The excellent properties of nanocomposites depend on the performance of nanoparticles such as type, particle size, filling concentration, and surface treatment, which have an important influence on the recrystallization process of nanocomposites. Crystallization behavior of nanocomposites play a crucial role in morphologies and the resulting properties to some extent, and the crystallization is regarded as a naturally self-assembly process $[4,5]$. In the process, the filler particles and other impurities in the nanocomposites are rejected from the crystal phase and incorporated into the amorphous region [6]. Recently, Zheng et al. investigated the structure and morphology of the polyamide-6/ZnO nanocomposites and reported that the $\mathrm{ZnO}$ nanoparticles can induce the crystallization of the $\gamma$-crystalline form PA- 6 from the melt and during the annealing of the amorphous solid [7].

Recently, titanium dioxide $\left(\mathrm{TiO}_{2}\right)$ being regarded as a filler embedded in polymer matrix has been reported frequently, because of its stability and optical and electronic properties [8-12]. Titanium dioxide has two common crystal forms: anatase phase and rutile phase; anatase can be converted into rutile under high temperature, usually greater than $900^{\circ} \mathrm{C}$, but the process is irreversible. Nanoanatase is usually used as photocatalyst because of its wide and direct band gap of $3.2 \mathrm{eV}$, while nanorutile is widely doped in Epoxy resin, polypropylene, and other polymers to improve the ability of antiaging due to its strong ability to absorb 
ultraviolet light [13]. Nelson and Fothergill researched the permittivity and dielectric loss of Epoxy/Micro- $\mathrm{TiO}_{2}$ and Epoxy/Nano- $\mathrm{TiO}_{2}$ nanocomposites. It is reported that the permittivity of Epoxy/Micro- $\mathrm{TiO}_{2}$ is larger compared to the Epoxy/Nano- $\mathrm{TiO}_{2}$ and polymer matrix, while the permittivity of Epoxy/Nano- $\mathrm{TiO}_{2}$ is smaller compared to the polymer matrix and Epoxy/Micro- $\mathrm{TiO}_{2}$ [10]. Tomara et al. also pointed that the dielectric response of the $\mathrm{TiO}_{2}$ nanocomposites compared to that of the $\mathrm{TiO}_{2}$ microcomposites reveals that the former exhibit significantly higher energy storage efficiency even at lower $\mathrm{TiO}_{2}$ concentration than the microcomposites [11]. The dielectric properties of $\mathrm{LDPE} / \mathrm{TiO}_{2}$ nanocomposites were researched by Zazoum et al., and it was considered that the improved dielectric properties could be related to the good dispersion of the $\mathrm{TiO}_{2}$ nanoparticles due to the modification of surface [12].

The existing researches on the polyethylene/ $\mathrm{TiO}_{2}$ nanocomposites show that the improved properties of nanocomposites had been gradually recognized and interpreted through many theoretical models. However, these excellent properties are only for unaged nanocomposites, and the properties of aged nanocomposites have not been fully understood. In addition, researches had indicated that the maximum operating temperature of cable insulation can reach $90^{\circ} \mathrm{C}$, and the good dielectric properties of insulation material may bring some unwanted drawbacks to its performance under high temperature condition $[14,15]$. Therefore, it is necessary to further research the thermal aging behaviors of polyethylene/ $\mathrm{TiO}_{2}$ nanocomposites.

In this paper, the rutile $\mathrm{TiO}_{2}$ nanoparticles were selected as filler embedded in LDPE matrix with different mass fractions ( $0.5 \mathrm{wt} \%, 1 \mathrm{wt} \%, 3 \mathrm{wt} \%$, and $5 \mathrm{wt} \%)$. The Pure-LDPE and $\mathrm{LDPE} / \mathrm{TiO}_{2}$ film samples with the thickness of about $150 \mathrm{um}$ were aged in a vacuum oven at $90^{\circ} \mathrm{C}$ and taken out regularly (14 D, 35 D, 56 D, and 77 D) for the measurement of SEM, FTIR, DSC, and dielectric properties.

\section{Experiments}

2.1. Sample Preparation. Raw material is LDPE particles produced by borealis, with density $0.910 \sim 0.925 \mathrm{mg} / \mathrm{cm}^{3}$, melt index $2.1 \sim 2.2 \mathrm{~g} / 10 \mathrm{~min}$, and melting point $112^{\circ} \mathrm{C}$. Rutile $\mathrm{TiO}_{2}$ nanoparticles were selected as filler, with diameter $20 \sim 25 \mathrm{~nm}$, which were added to LDPE matrix with different mass concentrations ( $0.5 \mathrm{wt} \%, 1 \mathrm{wt} \%, 3 \mathrm{wt} \%$, and $5 \mathrm{wt} \%)$. Sample preparation method is as follows: $\mathrm{LDPE} / \mathrm{TiO}_{2}$ mixture was prepared by melting blend in an opened type mixer at $180^{\circ} \mathrm{C}$; $\mathrm{LDPE} / \mathrm{TiO}_{2}$ film samples with the thickness of about $150 \mu \mathrm{m}$ were prepared by a flat vulcanizing machine, maintained $10 \mathrm{~min}$ at $160^{\circ} \mathrm{C}$ and $10 \mathrm{MPa}$; the film samples were placed in a vacuum oven for $48 \mathrm{~h}$ at $80^{\circ} \mathrm{C}$, in order to eliminate the residual stress and the low molecular byproducts during sample preparation process [16]. The film samples with different mass concentrations are as shown in Figure 1. Lastly, the Pure-LDPE and $\mathrm{LDPE} / \mathrm{TiO}_{2}$ film samples were aged in a constant temperature aging oven at $90^{\circ} \mathrm{C}$ (aging belongs to thermal-oxidative aging because of some oxygen remains in the aging oven), which were taken out regularly (14 D, $35 \mathrm{D}, 56 \mathrm{D}$, and $77 \mathrm{D}$ ) for measurement of microstructure and
TABLE 1: Abbreviations of different samples.

\begin{tabular}{|c|c|c|c|}
\hline \multirow{2}{*}{$\begin{array}{l}\text { Filling mass } \\
\text { fraction }\end{array}$} & \multicolumn{3}{|c|}{ Aging days } \\
\hline & 0 days & $\ldots$ & 77 days \\
\hline $0 \mathrm{wt} \%$ & Pure-LDPE-0 D & $\cdots$ & Pure-LDPE-77 D \\
\hline$\ldots$ & $\cdots$ & $\cdots$ & $\ldots$ \\
\hline $5 \mathrm{wt} \%$ & $\mathrm{LDPE} / \mathrm{TiO}_{2}-5-0 \mathrm{D}$ & $\ldots$ & $\mathrm{LDPE} / \mathrm{TiO}_{2}-5-77 \mathrm{D}$ \\
\hline
\end{tabular}

electrical properties. Each sample has an abbreviation in the following section, as shown in Table 1.

2.2. SEM Results. Scanning electron microscope (SEM, JSM$6490 \mathrm{LV}$ made in Japan) was used to observe $\mathrm{TiO}_{2}$ nanoparticle dispersion and micromorphology of samples before and after thermal aging. The samples were treated with gold plating before testing, because LDPE belongs to nonmetallic material.

The SEM images of Pure-LDPE and $\mathrm{LDPE} / \mathrm{TiO}_{2}$ samples are shown in Figure 2. The "white dots" marked by green small circles in Figure 2(b) represent $\mathrm{TiO}_{2}$ nanoparticles with different sizes. It can be seen that $\mathrm{TiO}_{2}$ nanoparticles are evenly distributed in LDPE matrix. Furthermore, many reticular structures could be clearly observed in the $\mathrm{LDPE} / \mathrm{TiO}_{2}$ 0.5 samples, and the microstructure of LDPE was changed due to the small size effect of nanoparticles. In addition, thermal aging had a significant effect on the structure of samples, causing the structure to become loose and rough. It can be explained by the FTIR and DSC measurements in the following parts, and macromolecular chains were broken and crystalline state was changed to amorphous area during thermal-oxidative aging, decreasing the crystallinity of LDPE [17]. There were no obvious gully structures in $\mathrm{LDPE} / \mathrm{TiO}_{2}$ 0.5 samples aged 77 days, indicating that the $\mathrm{LDPE} / \mathrm{TiO}_{2}$ samples had stronger ability of antithermal aging than PureLDPE samples.

2.3. FITR Results. Attenuated total reflection infrared spectrometer (ATR-FTIR, Nicolet 6700 made in America) was used to analyze the effect of thermal-oxidative aging on the chemical structure of samples. The reflective crystal is $\mathrm{ZnSe}$, the incident angle is $45^{\circ}$, the scanning frequency is 24 times, the wavenumber range is from $400 \mathrm{~cm}^{-1}$ to $4000 \mathrm{~cm}^{-1}$, and the resolution is $4 \mathrm{~cm}^{-1}$. In addition, one computer was connected to the spectrometer in order to receive and analyze date.

FTIR spectra of aged and unaged samples are shown in Figure 3, and functional groups corresponding to the wavenumber are shown in Table 2 . It is generally accepted that a large number of polar groups such as carboxyl, carbonyl, and hydroxyl will be generated in aged LDPE material, and the content of those groups can represent the degree of aging [18].

Samples aged for 35 days and Pure-LDPE samples exhibited stronger $\mathrm{C}=\mathrm{O}$ double bond FTIR signal compared to that of $\mathrm{LDPE} / \mathrm{TiO}_{2}$ in Figure 3(b). Furthermore, content of $\mathrm{C}=\mathrm{O}$ in aged $\mathrm{LDPE} / \mathrm{TiO}_{2}$ samples increased with filling concentration, because the oxygen is easier to diffuse into 


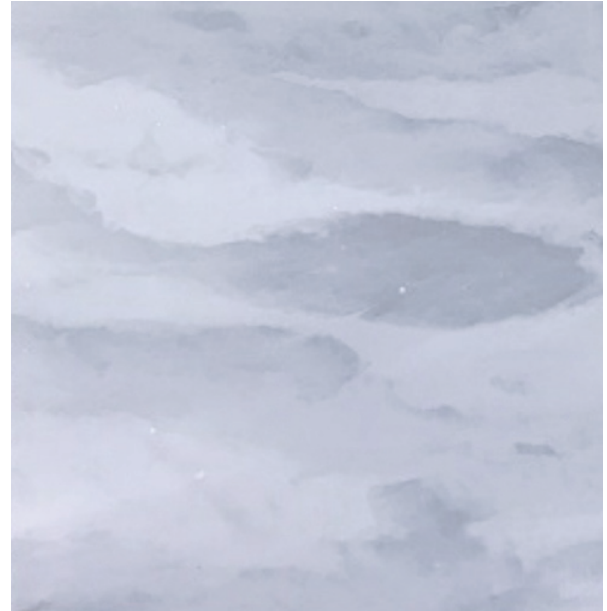

(a) $\mathrm{LDPE} / \mathrm{TiO}_{2}-0.5$

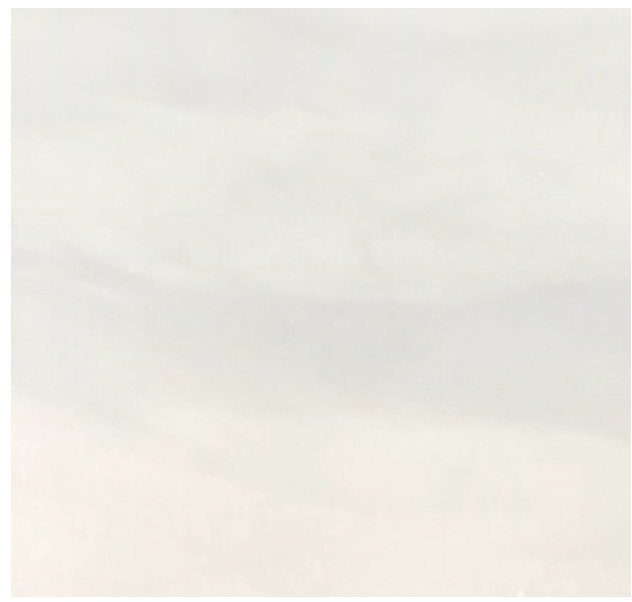

(c) $\mathrm{LDPE} / \mathrm{TiO}_{2}-3$

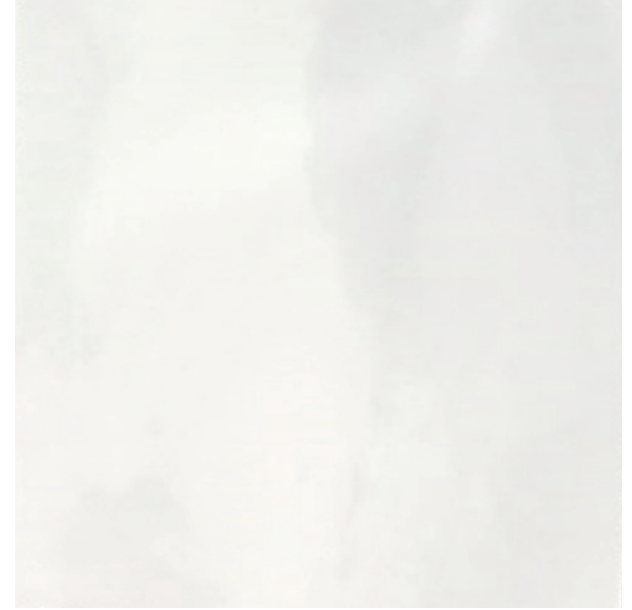

(b) $\mathrm{LDPE} / \mathrm{TiO}_{2}-1$

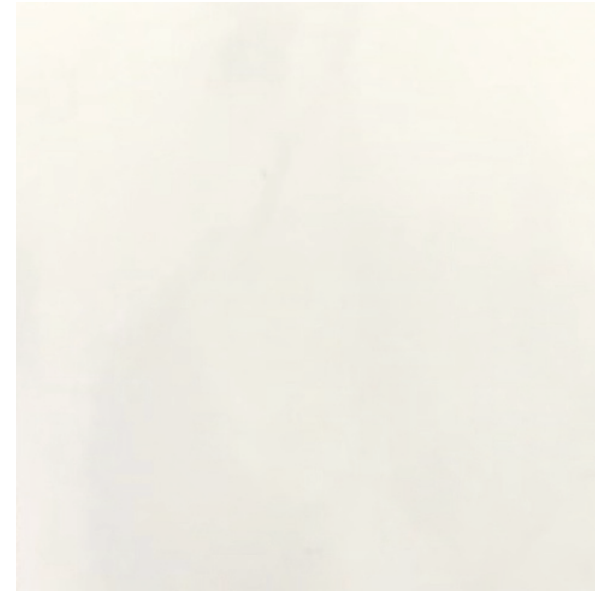

(d) $\mathrm{LDPE} / \mathrm{TiO}_{2}-5$

Figure 1: $\mathrm{LDPE} / \mathrm{TiO}_{2}$ samples with different mass fractions.

low crystallinity samples, and it has confirmed that the crystallinity of $\mathrm{LDPE} / \mathrm{TiO}_{2}$ samples decreased with filling concentration. Figure $3(\mathrm{~d})$ shows that the $\mathrm{C}=\mathrm{C}$ double bond gradually transformed to be $\mathrm{C}=\mathrm{O}$ double bond during the process of aging, which indicated sample was destroyed due to the synergistic action of heat and oxygen. The samples LDPE/ $\mathrm{TiO}_{2}-0.5$ had the best antiaging ability, however, which began showing aging characteristics until thermal aging of 77 days. The content of hydroxyl first decreased and then increased with the process of aging as shown in Figure 3(c), and the possible reason was that the moisture in the air is easily attached to the surface of unaged samples because of some static electricity produced during the preparation process. The content of hydroxyl first decreased because the moisture was dried at initial of aging and then increased because of the severe thermal oxygen aging.

2.4. DSC Results. The SETARAM-DSC 141 differential scanning calorimetry (DSC) was used to measure the crystallinity of different samples, the test temperature range is within $50^{\circ} \mathrm{C} \sim 160^{\circ} \mathrm{C}$, the heating rate is about $10^{\circ} \mathrm{C} / \mathrm{min}$, and the nitrogen flow rate is about $150 \mathrm{ml} / \mathrm{min}$.

The thermal flow melting curves of LDPE and $\mathrm{LDPE} / \mathrm{TiO}_{2}-0.5$ samples whose age is of different days are shown in Figure 4, which can be used to calculate the crystallinity of material, as shown in formula (1). The calculation results are shown in Table 3

$$
X_{C}=\frac{\Delta H_{m}}{H_{N}} \times 100 \%,
$$

where $X_{C}$ refers to crystallinity of polyethylene; $\Delta H_{m}$ refers to the melting heat and its value is the area surrounded by melting peak and baseline; $H_{N}$ refers to the melting heat when the crystallinity of polyethylene reached $100 \%$, and its value is about $293.6 \mathrm{~J} / \mathrm{g}$.

It can be seen from Table 3 that the crystallinity of polyethylene was increased by filling $\mathrm{TiO}_{2}$ nanoparticles, and it also indicated that the structure of $\mathrm{LDPE} / \mathrm{TiO}_{2}$ samples is more compact compared to Pure-LDPE samples. On 


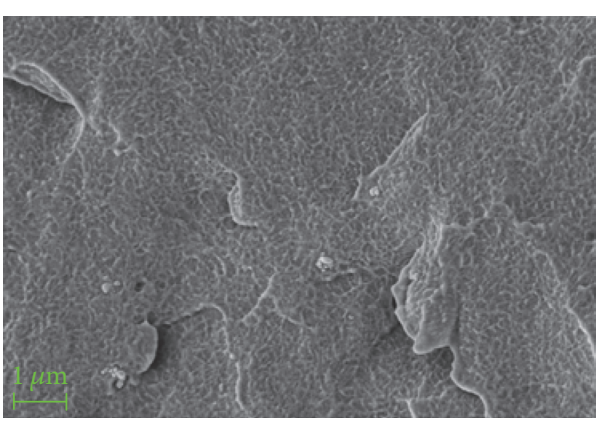

(a) Pure-LDPE-0 D

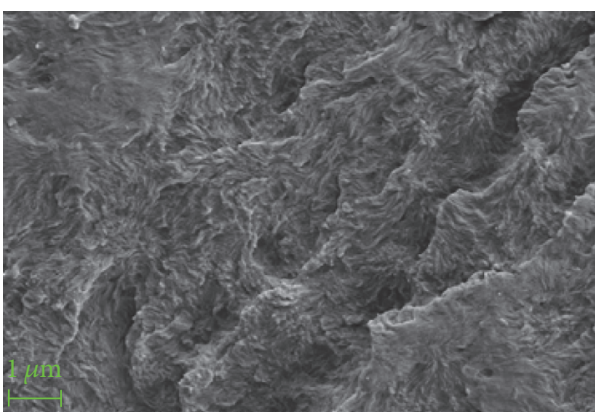

(c) Pure-LDPE-77 D

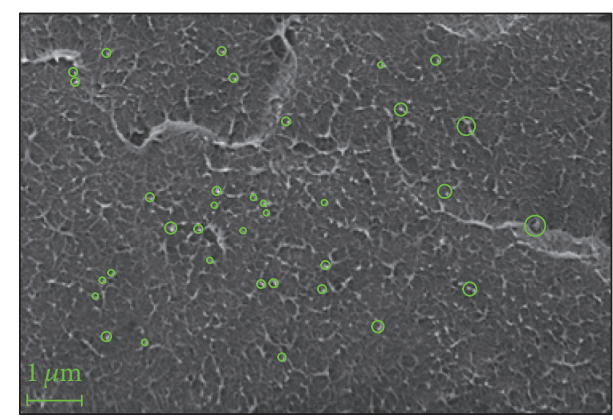

(b) $\mathrm{LDPE} / \mathrm{TiO}_{2}-0.5-0 \mathrm{D}$

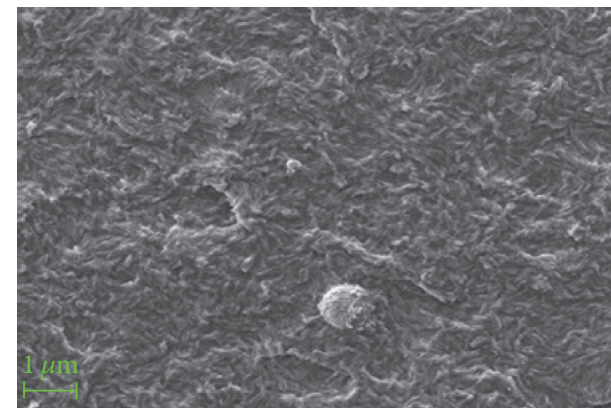

(d) $\mathrm{LDPE} / \mathrm{TiO}_{2}-0.5-77 \mathrm{D}$

FIGURE 2: SEM images of Pure-LDPE and LDPE/TiO ${ }_{2}$ samples.

the whole, the crystallinity of both LDPE and $\mathrm{LDPE} / \mathrm{TiO}_{2}$ 0.5 samples was decreased with aging time, but the crystallinity of $\mathrm{LDPE} / \mathrm{TiO}_{2}-0.5$ samples remained at a higher value compared to Pure-LDPE samples during thermal aging process. It can be concluded that filling $\mathrm{TiO}_{2}$ nanoparticles changed the crystallization behavior of polyethylene, which played a role of heterogeneous nucleation during the process of recrystallization, generating a large number of small spherulites, leading to the increasing of crystallinity. In addition, the crystallinity of samples with the age of 14 days was higher compared to the unaged samples. It is because of further completion of recrystallization process and low thermal degradation at the start of aging, resulting in further improvement of crystallinity of nanocomposites.

2.5. Dielectric Properties Measurement. The concept 80 testing system manufactured by Novocontrol Company was used to measure the real permittivity $\varepsilon^{\prime}$ and dielectric dissipation $\tan \delta$. The testing frequency range was from $10^{-1} \mathrm{~Hz}$ to $10^{6} \mathrm{~Hz}$ and the measurements were carried out at room temperature $(25 \pm 1)^{\circ} \mathrm{C}$.

The laws of real permittivity with frequency for unaged and aged samples are shown in Figure 5. It can be seen that the real permittivity of all samples decreased with the increase of frequency due to electron polarization and slight impurity polarization can be fully established in the low frequency range [19].

Unaged samples are shown in Figure 5(a), and the LDPE/ $/ \mathrm{TiO}_{2}-0.5$ samples had lower permittivity than PureLDPE, while the other $\mathrm{LDPE} / \mathrm{TiO}_{2}$ samples had higher permittivity than Pure-LDPE. What is more, the permittivity of $\mathrm{LDPE} / \mathrm{TiO}_{2}$ nanocomposites first decreased and then increased with the increase of filling concentration. Figure 5(b) shows the samples aged 35 days, all $\mathrm{LDPE} / \mathrm{TiO}_{2}$ samples had lower permittivity than Pure-LDPE samples, and, in particular, the permittivity of $\mathrm{LDPE} / \mathrm{TiO}_{2}-0.5$ samples was significantly lower than others. It indicated that the $\mathrm{LDPE} / \mathrm{TiO}_{2}-0.5$ samples have ability of antithermal ageing, which could be verified by the results of FTIR in Figure 3(b). As can be seen in Figures 5(c) and 5(d), the samples aged 14 days had lower permittivity than unaged samples, and it may be due to the improving of crystallinity, which has been confirmed by the DSC measurement.

In addition, there existed a regular change between the permittivity and aging time, and the slope of permittivity curves increased with aging, which could characterize the degree of thermal aging. And the permittivity exhibited "jump increase" process, the change for Pure-LDPE samples was from 14 days to 35 days, while the change occurred from 56 days to 77 days for $\mathrm{LDPE} / \mathrm{TiO}_{2}-0.5$ samples. It could also be proved that the $\mathrm{LDPE} / \mathrm{TiO}_{2}-0.5$ samples have ability of antithermal aging.

Figure 6 shows the law of dissipation factor with frequency for unaged and aged samples. For unaged samples, the dielectric loss was very low and a loss peak $\beta$ was distinctly observed, which gradually shifted to lower frequency with the increase of nanoparticles filling concentration. For the aged samples, however, a new loss peak $\alpha$ was found between $10^{1} \mathrm{~Hz}$ and $10^{2} \mathrm{~Hz}$, the height of which increased with aging. In addition, the dielectric loss in both low frequency band and high frequency band was increased significantly for aged 
TABLE 2: FTIR functional groups corresponding to the wavenumber.

\begin{tabular}{lcc}
\hline Number & Wavenumber/cm ${ }^{-1}$ & Vibration type of bond \\
\hline 1 & $3650 \sim 3200$ & $-\mathrm{OH}$ stretching vibration \\
2 & $2916 \sim 2936 / 2843 \sim 2863$ & $\mathrm{C}-\mathrm{H}$ single bond stretching vibration \\
3 & $1740 \sim 1690$ & $\mathrm{C}=\mathrm{O}$ double bond stretching vibration \\
4 & $1695 \sim 1540$ & $\mathrm{C}=\mathrm{C}$ double bond stretching vibration \\
5 & $1445 \sim 1485 / 722$ & $-\mathrm{CH}_{2}-$ deformation vibration \\
6 & $600 \sim 400$ & $\mathrm{TiO}_{2}$ spectrum absorption peak \\
\hline
\end{tabular}

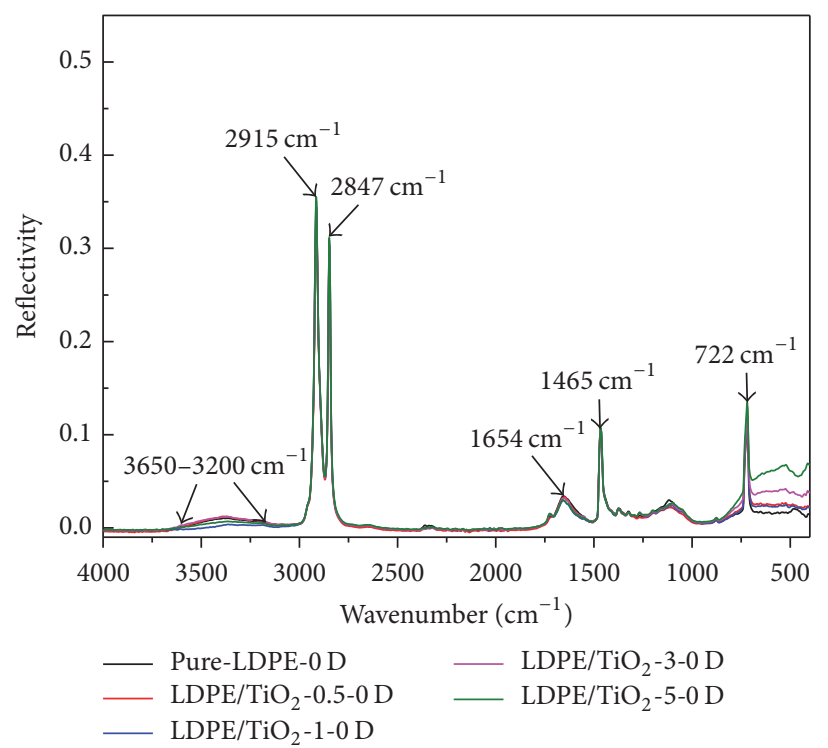

(a) Unaged samples

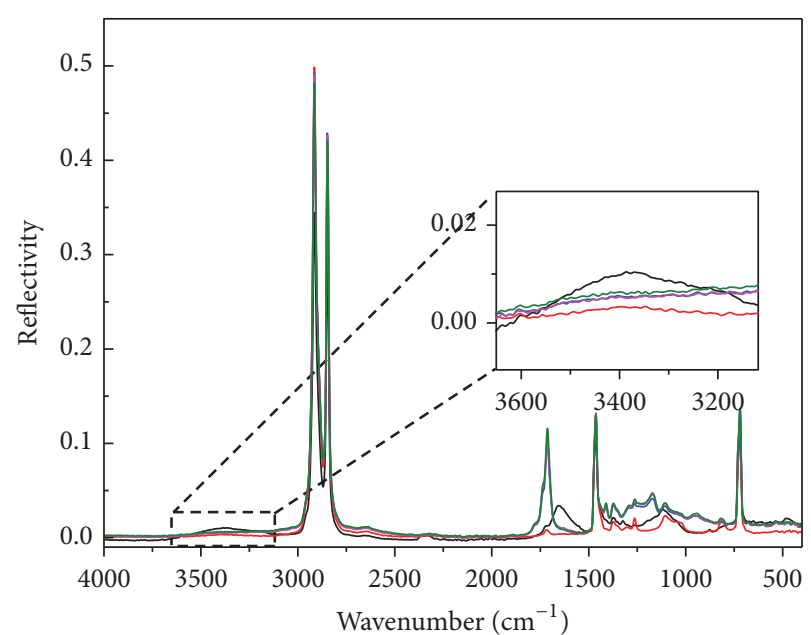

$\begin{array}{ll}\text { Pure-LDPE-0 D } & \text { Pure-LDPE-56 D } \\ \text { Pure-LDPE-14 D } & \text { Pure-LDPE-77 D }\end{array}$

— Pure-LDPE-35 D

(c) Pure-LDPE aged different days

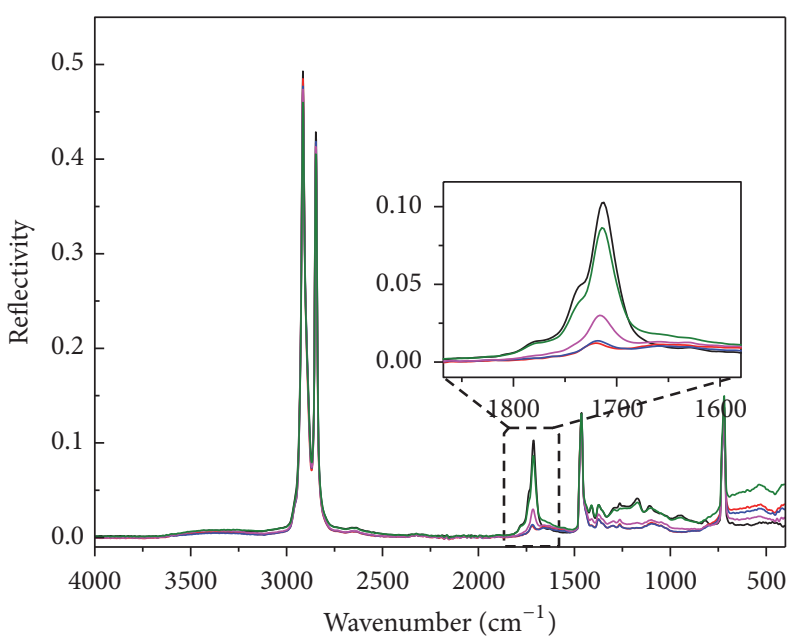

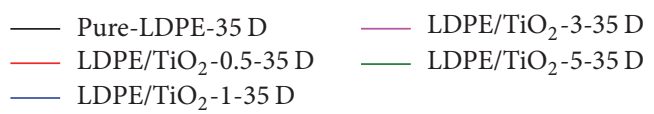

(b) Samples aged 35 days
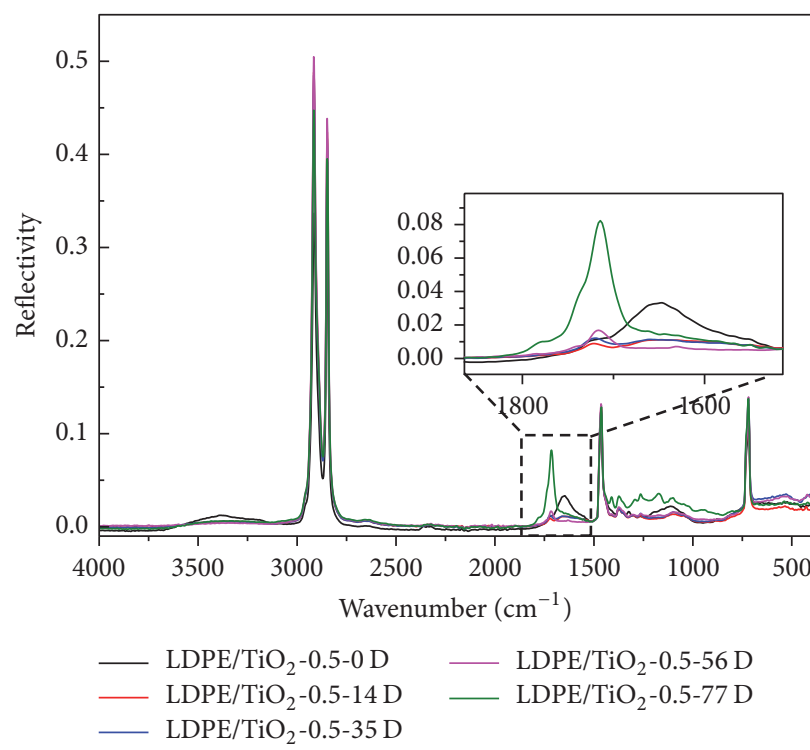

(d) $\mathrm{LDPE} / \mathrm{TiO}_{2}-0.5$ aged different days

FIGURE 3: The FTIR spectra of aged and unaged samples. 
TABLE 3: Crystallinity of Pure-LDPE and LDPE/TiO $2-0.5$ samples aged different days.

\begin{tabular}{|c|c|c|c|c|}
\hline \multirow{2}{*}{ Aging days } & \multicolumn{2}{|c|}{ Pure-LDPE } & \multicolumn{2}{|c|}{$\mathrm{LDPE} / \mathrm{TiO}_{2}-0.5$} \\
\hline & $\Delta H_{m}$ & $X_{C}$ & $\Delta H_{m}$ & $X_{C}$ \\
\hline $0 \mathrm{D}$ & 147.18 & 50.12 & 154.84 & 52.74 \\
\hline $14 \mathrm{D}$ & 136.73 & 51.56 & 152.14 & 54.82 \\
\hline $35 \mathrm{D}$ & 131.50 & 44.78 & 141.99 & 48.36 \\
\hline $56 \mathrm{D}$ & 129.89 & 44.23 & 137.87 & 46.96 \\
\hline $77 \mathrm{D}$ & 115.91 & 39.47 & 134.03 & 45.65 \\
\hline
\end{tabular}

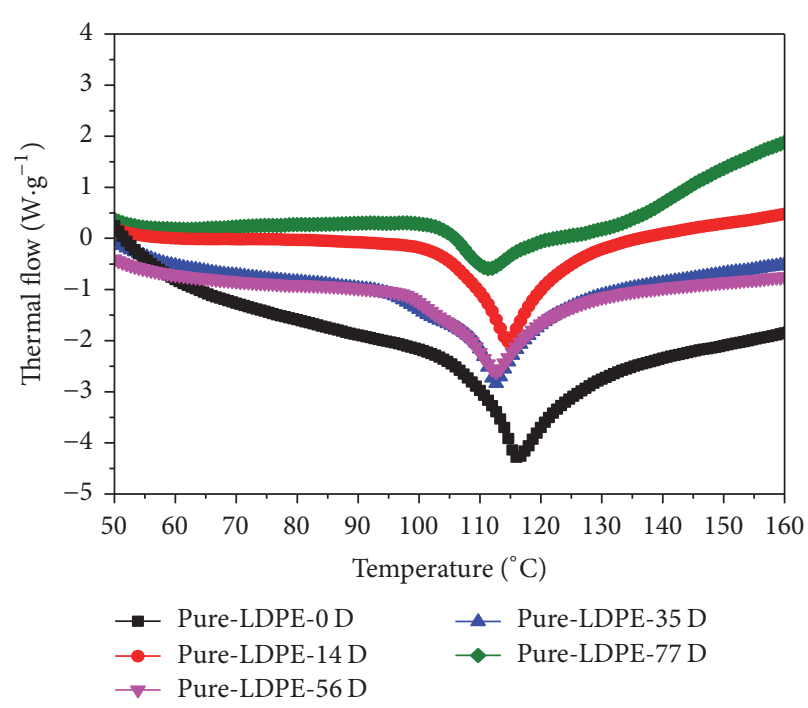

(a) Pure-LDPE

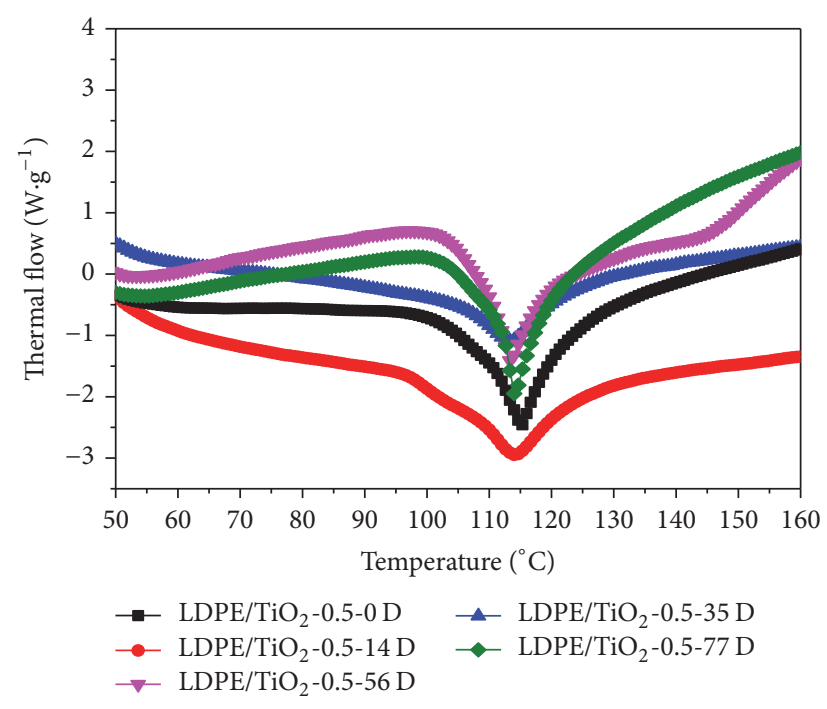

(b) $\mathrm{LDPE} / \mathrm{TiO}_{2}-0.5$

FIgURE 4: Thermal flow curves of samples with different aging days.

samples, and the shapes of dissipation factor spectra were changed from "single hump" to "W." Actually, Figure 6 corresponds to Figure 5, it also can illustrate that the $\mathrm{LDPE} / \mathrm{TiO}_{2}$ samples have the ability of antithermal ageing.

\section{Discussions}

3.1. Thermal-Oxidative Aging Mechanism of LDPE and $L D P E / \mathrm{TiO}_{2}$. LDPE will be oxidized under thermal and aerobic conditions, which is a chain free radical reaction and can be divided into three stages, regarded as "chain initiation," "chain growth," and "chain termination," respectively [20]. The three stages are shown in formulas (2), (3), and (4), respectively. Actually, the "chain initiation" is a slow process, which is generally not easy to happen, because the oxygen only contacts with the surface of material and cannot diffuse into material. The period before "chain initiation" is described as "induced oxidation period," and it can reflect the antiaging ability of material. However, the "chain growth" is a rapid aging process described as "accelerated oxidation period," because the material structure becomes loose and the oxygen is easy to diffuse into material. For the "chain termination" stage, LDPE is fully degraded, the reactive groups react with each other to form stable products, and the process of automatic oxygen inhalation is basically balanced, which can be described as "slow oxidation period."

$$
\mathrm{RH} \stackrel{\Delta / \mathrm{O}}{\longrightarrow} \mathrm{ROOH} \longrightarrow \mathrm{R}^{\bullet}+{ }^{\circ} \mathrm{OOH}
$$

$$
\begin{aligned}
\mathrm{R}^{\bullet}+\mathrm{O}_{2} & \rightarrow \mathrm{ROO}^{\bullet} \\
\mathrm{ROO}^{\bullet}+\mathrm{RH} & \longrightarrow \mathrm{ROOH}+\mathrm{R}^{\bullet} \\
\mathrm{ROOH} & \longrightarrow \mathrm{RO}^{\bullet}+{ }^{\circ} \mathrm{OH} \\
\mathrm{RO}^{\bullet}+\mathrm{RH} & \longrightarrow \mathrm{ROH}+\mathrm{R}^{\bullet} \\
\mathrm{R}^{\bullet}+\mathrm{R}^{\bullet} & \longrightarrow \mathrm{R}-\mathrm{R} \\
\mathrm{R}^{\bullet}+\mathrm{ROO}^{\bullet} & \longrightarrow \mathrm{ROOR} \\
\mathrm{ROO}^{\bullet}+\mathrm{ROO}^{\bullet} & \longrightarrow \mathrm{ROOR}+\mathrm{O}_{2}
\end{aligned}
$$

where $\mathrm{R}^{\bullet}$ refers to the alkyl radicals such as $\mathrm{CH}_{3}{ }^{\bullet}$ or $-\mathrm{CH}_{2}{ }^{\bullet}$ and $\Delta / \mathrm{O}$ refers to the thermal and aerobic conditions.

It can be seen that lots of chemical defects such as carboxyl, carbonyl, and hydroxyl will be generated in LDPE material during thermal-oxidative aging, which can be confirmed by FTIR in Figure 3. At the same time, it can be seen from Figure 3 that the "oxidation induction period" of Pure-LDPE was 14 days, while that of $\mathrm{LDPE} / \mathrm{TiO}_{2}-0.5$ was 56 days. The small size effect and surface effect of nanoparticles changed the recrystallization process of $\mathrm{LDPE} / \mathrm{TiO}_{2}$, generating more small grains and lots of $\mathrm{LDPE} / \mathrm{TiO}_{2}$ interface regions, and consequently the crystallinity of $\mathrm{LDPE} / \mathrm{TiO}_{2}$ is higher compared to Pure-LDPE [6]. So, the oxygen is difficult to diffuse into material and hard to spread quickly inside of material due to compact structure of $\mathrm{LDPE} / \mathrm{TiO}_{2}$ 


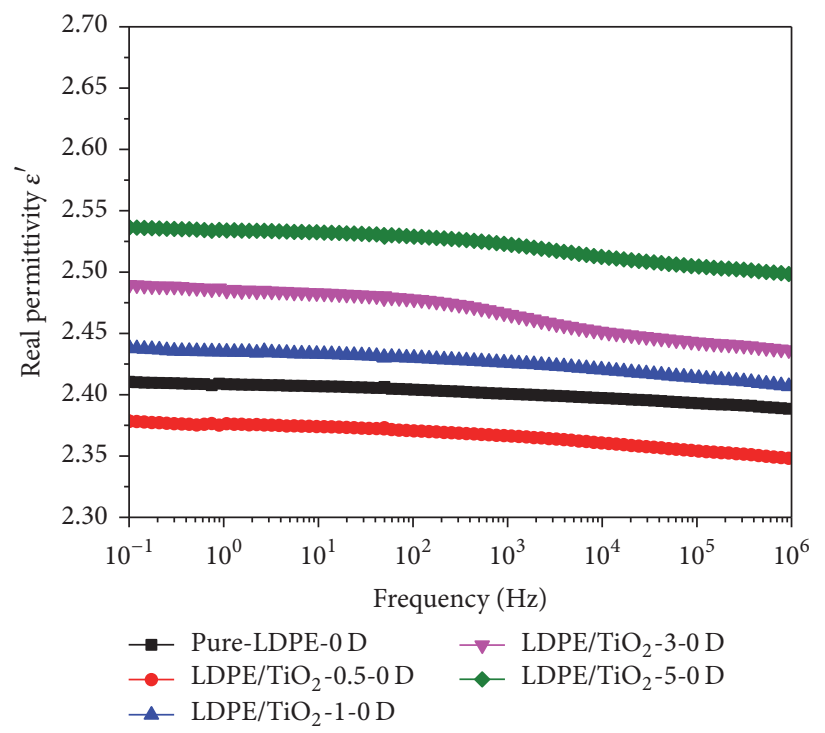

(a) Unaged samples

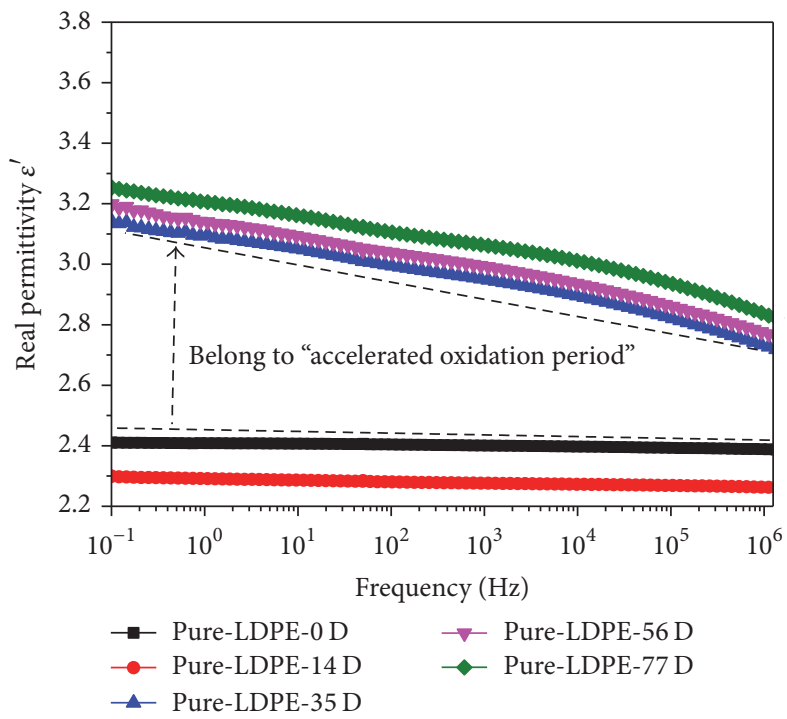

(c) Pure-LDPE aged different days

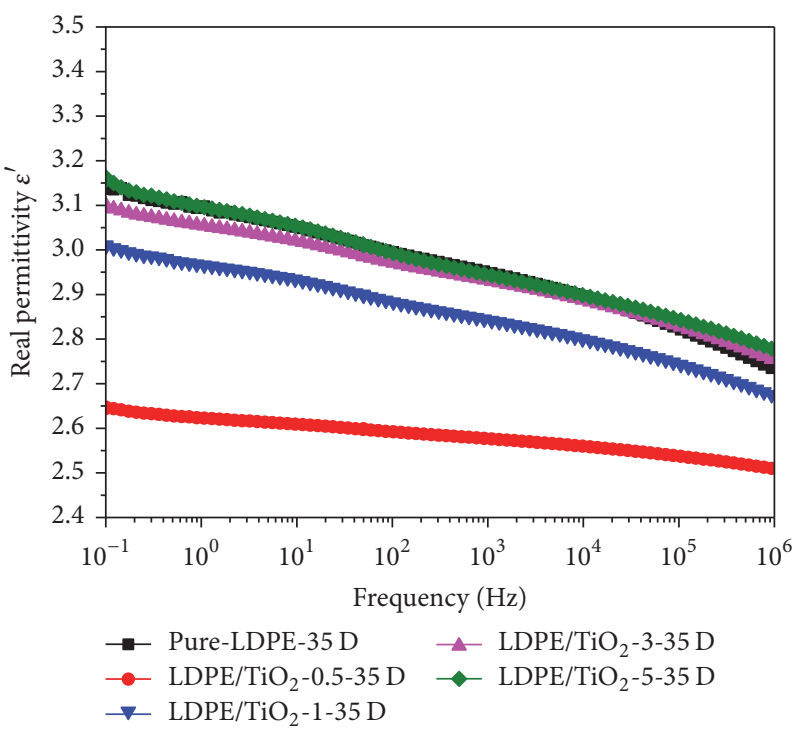

(b) Samples aged 35 days

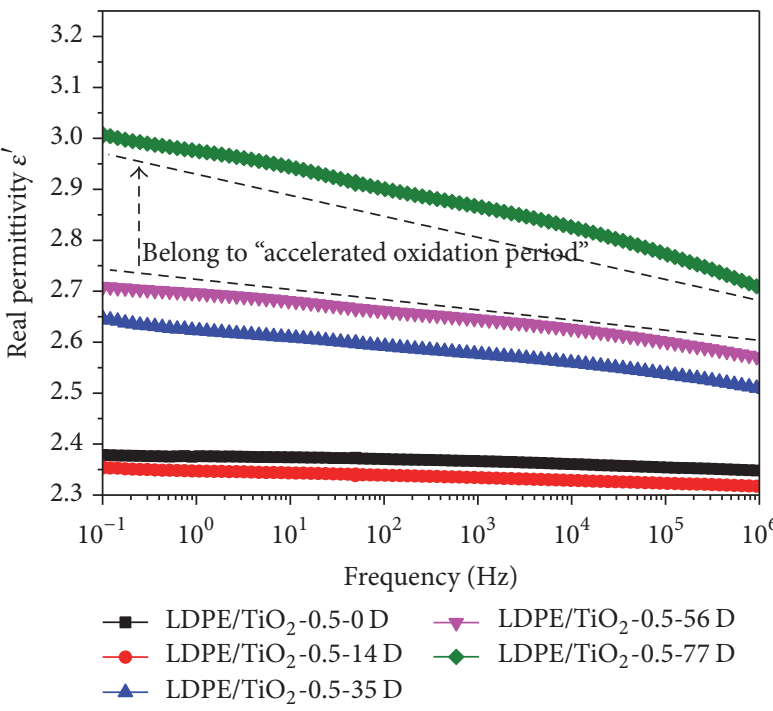

(d) $\mathrm{LDPE} / \mathrm{TiO}_{2}-0.5$ aged different days

FIGURE 5: The law of real permittivity with frequency.

nanocomposites, thereby enhancing the ability of thermaloxidative aging.

3.2. Effect of Thermal Aging on Dielectric Behaviors. The permittivity and dielectric loss can reflect the dielectric relaxation process in dielectric, which is usually as an important means to understand the structure and properties of dielectric and reveal the aging process of dielectric. The polymer/inorganic nanoparticles composite dielectrics consist of three parts: polymer matrix, inorganic nanoparticles, and interface region, which codetermines the dielectric properties of nanocomposites.

At present, it was confirmed in literatures that the permittivity of nanocomposites is larger than that of polymer matrix due to the large permittivity of nanoparticles and existing Maxwell-Wagner interfacial polarization [21]. It also can be verified by the proposed theoretical model such as Maxwell-Garnett model used to calculate the permittivity of nanocomposites [22]. The measured permittivity value of $\mathrm{LDPE} / \mathrm{TiO}_{2}$ is equal to 2.37 when the filling mass fraction is $0.5 \%$; however, the calculated value is 2.52 . This phenomenon cannot be explained by the traditional polarization theory. Tanaka et al. have proposed that the interfacial region introduced by filling nanoparticles has important effect on the permittivity of nanocomposites [23]. Strong interaction exists between polymer molecules and nanoparticles in interfacial region, causing that the structure of the material becomes more compact, which not only limits the movement of molecular chain but also forces the molecular chain into ordered arrays in amorphous region. The strong interaction can be described as "anchoring effect," as shown in Figure 7. Therefore, extremely low polarizability leads the $\mathrm{LDPE} / \mathrm{TiO}_{2}-0.5$ 


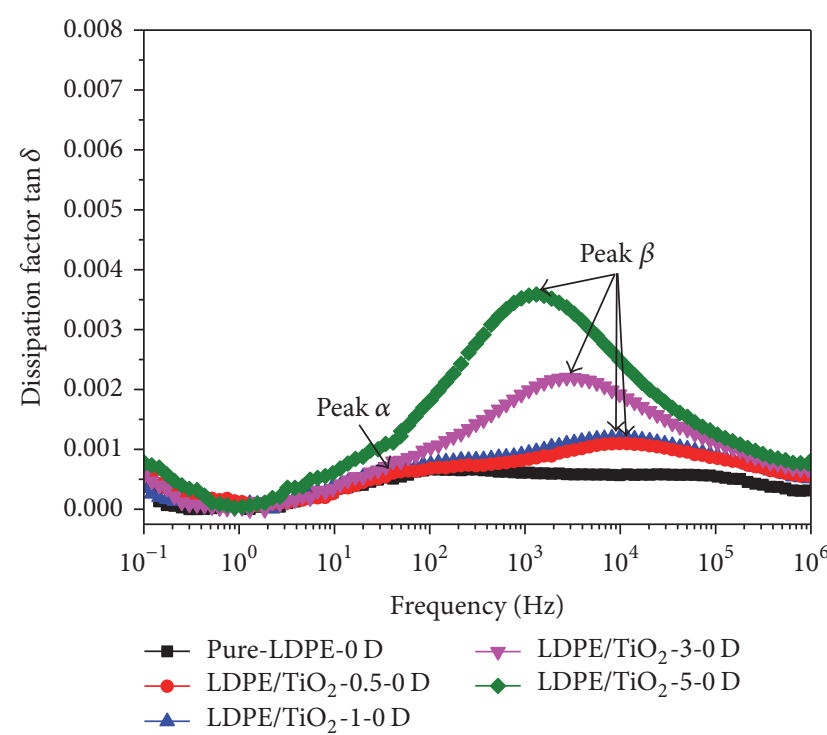

(a) Unaged samples

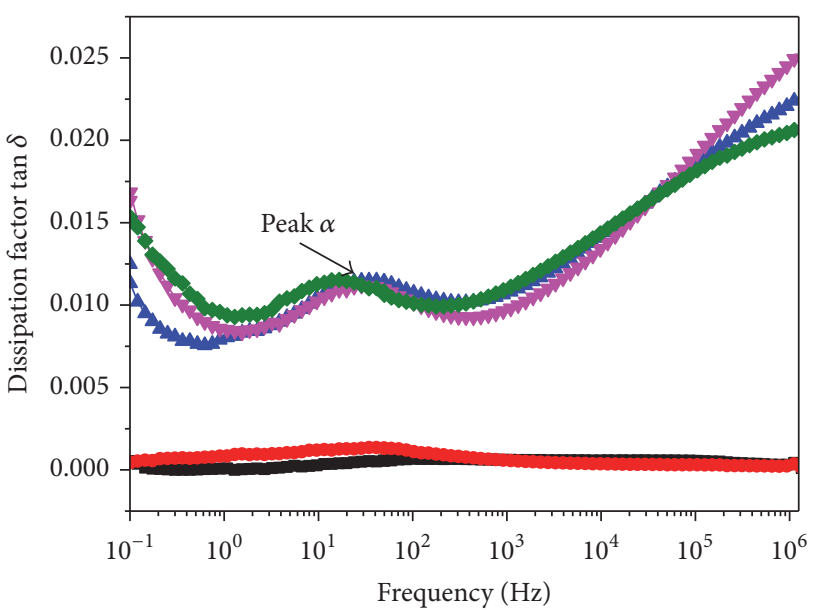

$\rightarrow$ Pure-LDPE-0 D $\rightarrow$ Pure-LDPE-56 D

$\multimap$ Pure-LDPE-14 D $\rightarrow$ Pure-LDPE-77 D

- Pure-LDPE-35 D

(c) Pure-LDPE aged different days

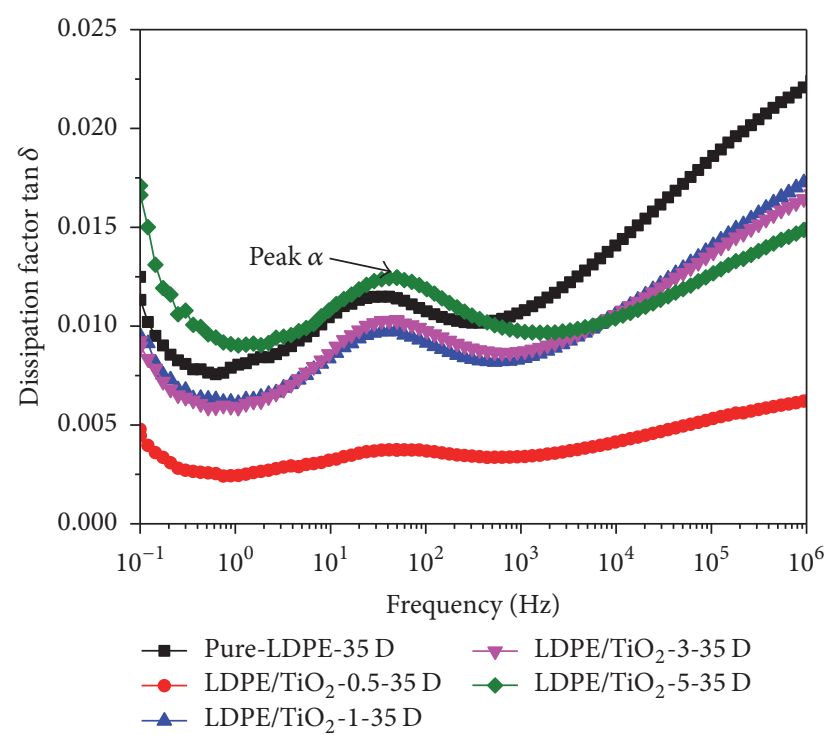

(b) Samples aged 35 days

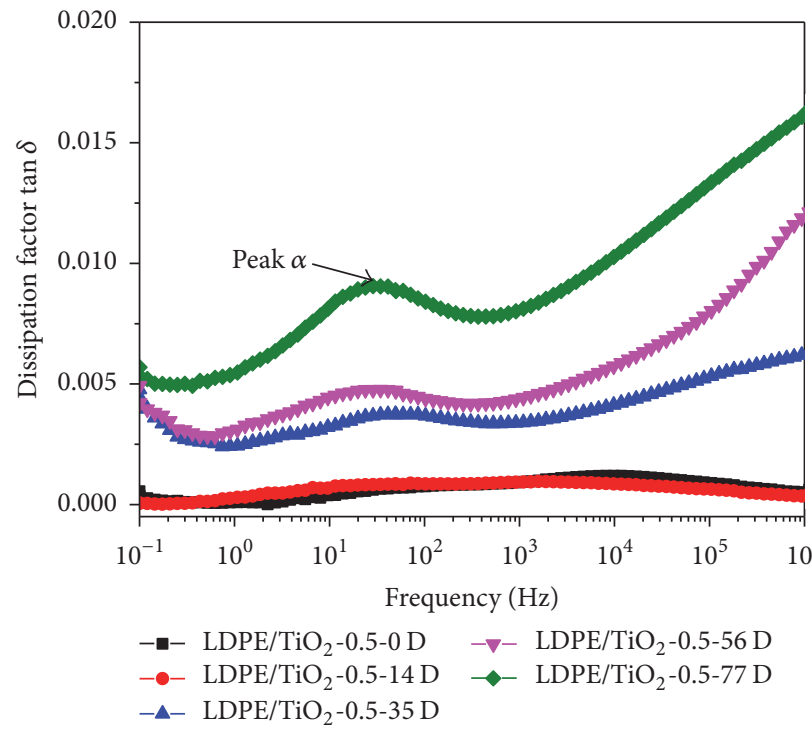

(d) $\mathrm{LDPE} / \mathrm{TiO}_{2}-0.5$ aged different days

FIGURE 6: The law of dissipation factor with frequency.

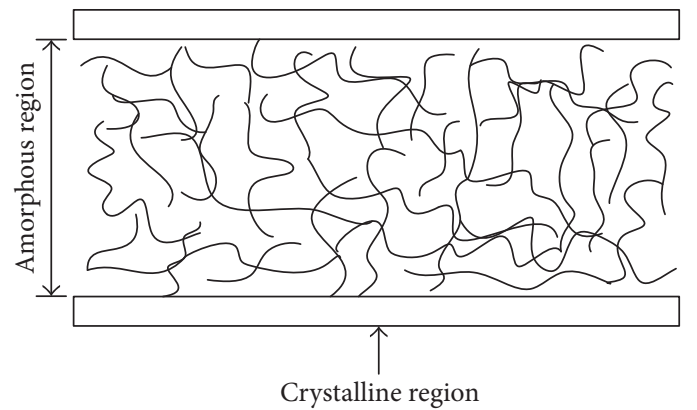

(a) Pure-LDPE

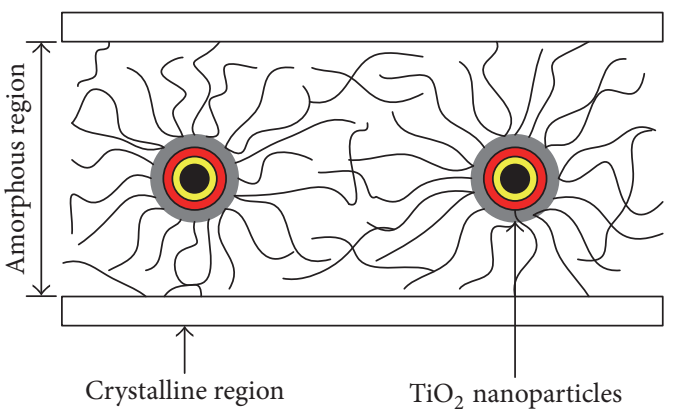

(b) $\mathrm{LDPE} / \mathrm{TiO}_{2}$ nanocomposites

Figure 7: The structure model of Pure-LDPE and $\mathrm{LDPE} \mathrm{TiO}_{2}$. 


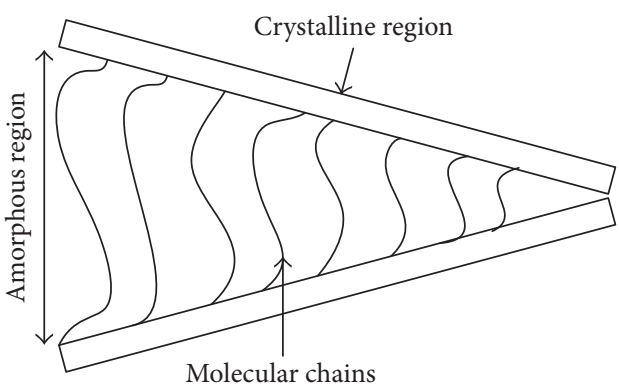

(a) Unaged Pure-LDPE samples

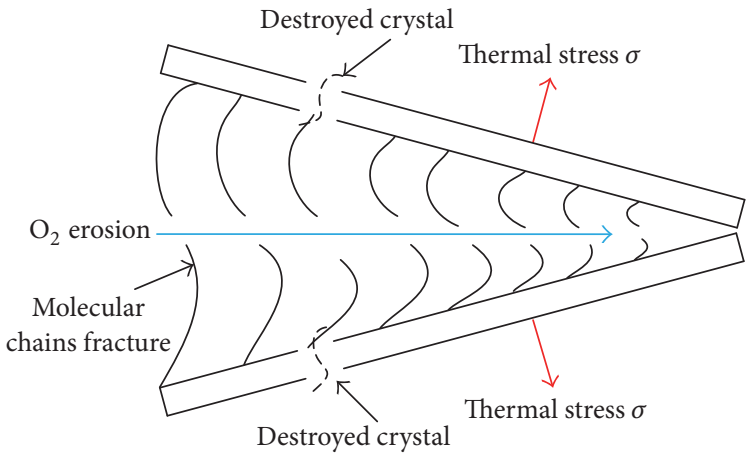

(c) Aged Pure-LDPE samples

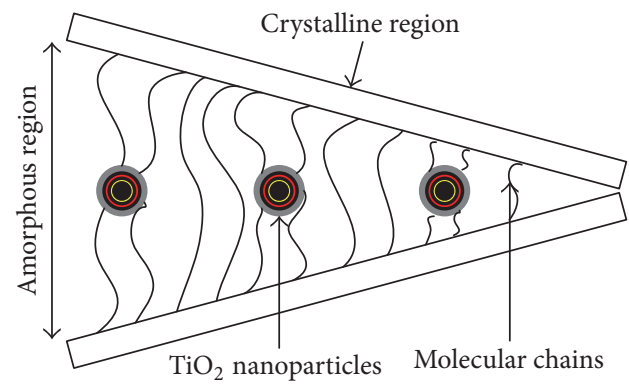

(b) Unaged $\mathrm{LDPE} / \mathrm{TiO}_{2}$ samples

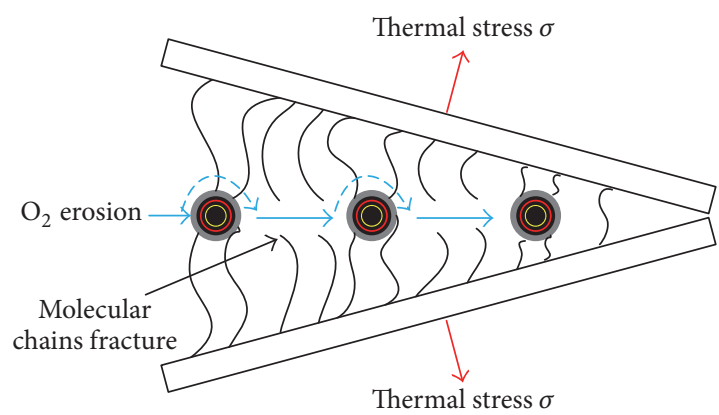

(d) Aged LDPE/TiO 2 samples

FIgURE 8: A new model for thermal-oxidative aging process.

samples to have lower permittivity than Pure-LDPE samples. However, the dispersion of nanoparticles becomes worse with the increase of filling concentration, the particle size of nanoclusters reaches micron level, Maxwell-Wagner interfacial polarization begins to show a dominant position, and the nanoparticle polarization cannot be ignored, and consequently the permittivity of $\mathrm{LDPE} / \mathrm{TiO}_{2}$ with high filling concentrations is larger than that of Pure-LDPE.

$$
\varepsilon_{f}=\frac{(2 m+1) \varepsilon_{1}+2(1-m) \varepsilon_{0}}{(1-m) \varepsilon_{1}+(2+m) \varepsilon_{0}} \varepsilon_{0},
$$

where $\varepsilon_{f}, \varepsilon_{0}$, and $\varepsilon_{1}$ refer to the permittivity of nanocomposites, the permittivity of polymer matrix $\left(\varepsilon_{0}=2.4\right.$, LDPE), and the permittivity of nanoparticles $\left(\varepsilon_{1}=48, \mathrm{TiO}_{2}\right)$, respectively, and $m$ refers to the volume fraction of nanoparticles.

In addition, the FTIR results had confirmed that large number of polar groups such as carboxyl, carbonyl, and hydroxyl would be generated during thermal-oxidative aging, and thus the impurity polarization was the main reason for the increasing of permittivity for aged samples. The aged $\mathrm{LDPE} / \mathrm{TiO}_{2}$ samples, however, had lower permittivity than the Pure-LDPE aged samples also due to their compact structure, which can reduce oxygen immersing into materials.

In Figure 6, the height of loss peak $\alpha$ increased with aging process, which is a typical Debye relaxation process. It is known that free radical, terminal group, and fracture of polymer can all create charge traps [24]. The carriers such as the injected electron or some charged small chain segments which usually exist in amorphous area and the interface between crystalline and amorphous area may easily fall into the trap and become the trapped charge [25]. The carries have enough time to achieve a high energy to escape from the shallow traps in low frequency band. The carrier motion is in a capturing, releasing, migrating and recapturing process, forming conductive current [26]. In high frequency band, however, the detrapping process of carriers becomes difficult and easy to form interface charges, generating Maxwell-Wagner interfacial polarization loss. Therefore, it can be considered that the dielectric loss is almost contributed by conduction loss in low frequency band, while that is almost contributed by interfacial polarization loss in high frequency band.

For aged samples, many impurities generated during thermal aging process are ionized to be charged ions, increasing the conduction loss. In addition, the structure of aged samples becomes loose and a large number of structural defects are generated, increasing trap level and trap density of samples. It aggravates the accumulation of interfacial charge and increases the interfacial loss. Accordingly, the dielectric loss in both low frequency band and high frequency band was increased significantly for aged samples. In particular, the aged $\mathrm{LDPE} / \mathrm{TiO}_{2}$ samples had lower dielectric loss than the Pure-LDPE aged samples, and the possible reason was that the $\mathrm{LDPE} / \mathrm{TiO}_{2}$ samples had more compact structure and the oxygen could not easily diffuse into materials to destroy macromolecular chains.

3.3. A New Model Proposed for Thermal-Oxidative Aging Process. A new model was proposed for thermal-oxidative aging process of cable insulation material based on the above experimental results in order to analyze the aging process of LDPE from a microscopic perspective. The model is shown in Figure 8. 
LDPE is a semicrystalline material composed of crystalline and amorphous regions. Thermal aging is essentially the oxidation reaction in thermal field. A thermal stress $\sigma$ will be generated whose direction is perpendicular to crystal due to uneven temperature distribution in thermal field [27]. The thermal stress will cause the Van Edward bond fracture, macromolecular chain fracture, and the increase of free volume under the condition of thermal-oxidative aging, forming large number of micropores and low density areas. Oxygen is easier to diffuse into LDPE with serious thermal aging, accelerating the destruction of molecular chain. With the further serious aging, the crystalline region is destroyed and gradually changed to amorphous region, and the micropores and low density areas become larger and larger until the insulation of LDPE is completely ineffective.

For the $\mathrm{LDPE} / \mathrm{TiO}_{2}$ samples, however, the $\mathrm{TiO}_{2}$ nanoparticles play the role of "crosslinking point" between LDPE molecular chains, strengthening the interaction between the LDPE molecular chains. The structure of $\mathrm{LDPE} / \mathrm{TiO}_{2}$ nanocomposites becomes more compact, which can reduce oxygen immersing into materials to break molecular structure. The $\mathrm{LDPE} / \mathrm{TiO}_{2}$ samples had high macromolecular chain regularity and crystallinity; therefore, the aged LDPE/TiO2 samples had lower permittivity and dielectric dissipation than Pure-LDPE aged samples. It is concluded that the $\mathrm{LDPE} / \mathrm{TiO}_{2}$ nanocomposites have a certain ability to delay aging under the condition of thermal-oxidative aging.

\section{Conclusion}

The work presented in this paper concerns with the microstructure, FTIR, and dielectric behaviors of Pure-LDPE and $\mathrm{LDPE} / \mathrm{TiO}_{2}$ nanocomposite. Several significant findings were concluded as follows.

(1) The results of SEM images showed that the microstructure of LDPE was changed and many reticular structures were generated due to filling $\mathrm{TiO}_{2}$ nanoparticles. In addition, thermal aging had a significant effect on the structure of samples, causing the structure to become loose and rough, but no obvious gully structure was found in aged $\mathrm{LDPE} / \mathrm{TiO}_{2}$ samples. The DSC measurement indicated that filling $\mathrm{TiO}_{2}$ nanoparticles changed the crystallization behavior of LDPE, played a role of heterogeneous nucleation during the process of recrystallization, and improved the crystallinity of $\mathrm{LDPE} / \mathrm{TiO}_{2}$. The FTIR spectra showed that the $\mathrm{C}=\mathrm{C}$ double bond gradually transformed to be $\mathrm{C}=\mathrm{O}$ double bond and the content of hydroxyl increased with the process of aging, indicating the LDPE was destroyed due to the synergistic action of heat and oxygen. Similarly, the FTIR spectra confirmed that the $\mathrm{LDPE} / \mathrm{TiO}_{2}$ nanocomposites with low filling concentration have ability of antithermal ageing.

(2) In the dielectric spectra of unaged and aged samples, the permittivity of $\mathrm{LDPE} / \mathrm{TiO}_{2}$ nanocomposites first decreased and then increased with the increase of filling concentration. There exists a strong relationship between thermal aging and increasing rate of permittivity in low frequency range, and the slope of permittivity curves could characterize the degree of thermal aging. In addition, the shape of dissipation factor spectra was changed from "single hump" to "W" and a new loss peak $\alpha$ was found between $10^{1} \mathrm{~Hz}$ and $10^{2} \mathrm{~Hz}$ with the process of thermal aging. Both the unaged and aged $\mathrm{LDPE} / \mathrm{TiO}_{2}-0.5$ samples had the lowest permittivity and dissipation factor because of good dispersion of the nanoparticles, and it indicated that the $\mathrm{LDPE} / \mathrm{TiO}_{2}$ 0.5 samples had excellent dielectric properties and significant ability of antithermal aging.

(3) A new model for thermal-oxidative aging process was proposed to illustrate the development of microscopic defects. It was suggested that oxygen may diffuse into LDPE materials to destroy the molecular structure during the process of thermal aging, the crystalline region was gradually changed to amorphous region, and the micropores and low density areas became larger and larger with the further serious aging. However, the $\mathrm{TiO}_{2}$ nanoparticles played the role of "crosslinking points" between LDPE molecular chains, strengthening the interaction between the LDPE molecular chains, and the compact structure of $\mathrm{LDPE} / \mathrm{TiO}_{2}$ samples could reduce oxygen immersing into LDPE materials. Therefore, the $\mathrm{LDPE} / \mathrm{TiO}_{2}$ samples had a certain ability to delay thermal-oxidative aging.

\section{Conflicts of Interest}

The authors declare that they have no financial or personal relationship with any people or any organization that may inappropriately influence their work and that there is no professional or commercial interest of any kind in all of the commercial entities mentioned in their paper.

\section{Acknowledgments}

The reported research was performed due to the Funds for National Key Basic Research Program of China (973 Program). The Contract Grant no. is 2015CB251003.

\section{References}

[1] W. L. Zhang, Y. Dai, H. Zhao, and L. Zhong, "Influence of nanocomposites of LDPE doped with nano-MgO by different preparing methods on its dielectric properties," Journal of Nanomaterials, vol. 2015, Article ID 146260, 6 pages, 2015.

[2] A. Ameli, M. Nofar, C. B. Park, P. Pötschke, and G. Rizvi, "Polypropylene/carbon nanotube nano/microcellular structures with high dielectric permittivity, low dielectric loss, and low percolation threshold," Carbon, vol. 71, no. 7, pp. 206-217, 2014.

[3] I. M. Alwaan, A. Hassan, and M. A. M. Piah, "Effect of zinc borate on mechanical and dielectric properties of metallocene linear low-density polyethylene/rubbers/magnesium oxide composite for wire and cable applications," Iranian Polymer Journal, vol. 24, no. 4, pp. 279-288, 2015.

[4] J.-T. Xu, W. Jin, G.-D. Liang, and Z.-Q. Fan, "Crystallization and coalescence of block copolymer micelles in semicrystalline block copolymer/amorphous homopolymer blends," Polymer, vol. 46, no. 5, pp. 1709-1716, 2005.

[5] T. J. Lewis, "Interfaces are the dominant feature of dielectrics at the nanometric level," IEEE Transactions on Dielectrics and Electrical Insulation, vol. 11, no. 5, pp. 739-753, 2004. 
[6] H. Yan, C. Li, and J. Zhou, "Effects of a-site (NaCe) substitution with $\mathrm{Na}$-deficiency on structures and properties of CaBi4Ti4O15-based high-curie-temperature ceramics," Japanese Journal of Applied Physics, vol. 40, no. 11, pp. 893-901, 2001.

[7] J. Zheng, R. W. Siegel, and C. G. Toney, "Polymer crystalline structure and morphology changes in nylon-6/ZnO nanocomposites," Journal of Polymer Science Part B Polymer Physics, vol. 41, no. 10, pp. 1033-1050, 2003.

[8] G. A. Kontos, "Electrical relaxation dynamics in $\mathrm{TiO} 2$ - polymer matrix composites," Express Polymer Letters, vol. 1, no. 12, pp. 781-789, 2007.

[9] A. Sodagar, S. Khalil, M. Z. Kassaee, A. S. Shahroudi, B. Pourakbari, and A. Bahador, "Antimicrobial properties of poly (methyl methacrylate) acrylic resins incorporated with silicon dioxide and titanium dioxide nanoparticles on cariogenic bacteria," Journal of Orthodontic Science, vol. 5, no. 1, p. 7, 2016.

[10] J. K. Nelson and J. C. Fothergill, "Internal charge behaviour of nanocomposites," Nanotechnology, vol. 15, no. 5, pp. 586-595, 2004.

[11] G. N. Tomara, A. P. Kerasidou, A. C. Patsidis et al., "Dielectric response and energy storage efficiency of low content $\mathrm{TiO} 2$ polymer matrix nanocomposites," Composites Part A Applied Science Manufacturing, vol. 71, pp. 204-211, 2015.

[12] B. Zazoum, M. Frechette, and E. David, "LDPE/tio2 nanocomposites: effect of poss on structure and dielectric properties," IEEE Electrical Insulation and Dielectric Phenomena, vol. 23, no. 5, pp. 2505-2507, 2016.

[13] M. Landmann, E. Rauls, and W. G. Schmidt, "The electronic structure and optical response of rutile, anatase and brookite $\mathrm{TiO}_{2}$," Journal of Physics: Condensed Matter, vol. 24, no. 19, pp. 1614-1621, 2012.

[14] S. B. Dalal, R. S. Gorur, and M. L. Dyer, "Aging of distribution cables in service and its simulation in the laboratory," IEEE Electrical Insulation and Dielectric Phenomena, vol. 12, no. 1, pp. 139-146, 2005.

[15] C. Kim, Z. Jin, P. Jiang, Z. Zhu, and G. Wang, "Investigation of dielectric behavior of thermally aged XLPE cable in the highfrequency range," Polymer Testing, vol. 25, no. 4, pp. 553-561, 2006.

[16] Y. Wang, K. Xiao, C. Wang, L. Yang, and F. Wang, "Effect of nanoparticle surface modification and filling concentration on space charge characteristics in $\mathrm{TiO}_{2}$ /XLPE nanocomposites," Journal of Nanomaterials, vol. 2016, no. 8, pp. 1-10, 2016.

[17] A. Benítez, J. J. Sánchez, M. L. Arnal, A. J. Müller, O. Rodríguez, and G. Morales, "Abiotic degradation of LDPE and LLDPE formulated with a pro-oxidant additive," Polymer Degradation and Stability, vol. 98, no. 2, pp. 490-501, 2013.

[18] K. Yang, G.-J. Zhang, D.-M. Tu, and Z. Yan, "Space charge and electroluminescence characteristics of thermally aged LDPE films," Applied Surface Science, vol. 255, no. 5, pp. 2735-2739, 2008.

[19] R. Liao, G. Bai, L. Yang, H. Cheng, Y. Yuan, and J. Guan, "Improved electric strength and space charge characterization in LDPE composites with montmorillonite fillers," Journal of Nanomaterials, vol. 2013, Article ID 712543, pp. 1-7, 2013.

[20] S. Ito, Y. Tanaka, H. Yoshikawa, Y. Ishibashi, H. Miyasaka, and H. Masuhara, "Confinement of photopolymerization and solidification with radiation pressure," Journal of the American Chemical Society, vol. 133, no. 37, pp. 14472-14475, 2011.
[21] F. Rogti and M. Ferhat, "Maxwell-wagner polarization and interfacial charge at the multi-layers of thermoplastic polymers," Journal of Electrostatics, vol. 72, no. 1, pp. 91-97, 2014.

[22] M. Y. Koledintseva, R. E. DuBroff, and R. W. Schwartz, "A maxwell garnett model for dielectric mixtures containing conducting particles at optical frequencies," Progress in Electromagnetics Research, vol. 63, pp. 223-242, 2006.

[23] T. Tanaka, M. Kozako, and N. Fuse, "Proposal of a multi-core model for polymer nanocomposite dielectrics," IEEE Electrical Insulation and Dielectric Phenomena, vol. 12, no. 4, pp. 669-681, 2005.

[24] J. Li, X. Tong, and G. Yin, "The effect of accelerated water tree ageing on the properties of XLPE cable insulation," IEEE Electrical Insulation and Dielectric Phenomena, vol. 18, no. 5, pp. 1562-1569, 2011.

[25] Y. Hoshino and H. Miyata, "Thermally stimulated currents in amorphous selenium: relationship to trapping levels and the noncrystalline state," Journal of Applied Physics, vol. 52, no. 10, pp. 6214-6217, 1981.

[26] G. C. Montanari, G. Mazzanti, and F. Palmieri, "Investigation of charge transport and trapping in LDPE and HDPE through space charge and conduction current measurements," IEEE International Conference on Solid Dielectrics, pp. 240-244, 2001.

[27] J. P. Jones, J. P. Llewellyn, and T. J. Lewis, "The contribution of field-induced morphological change to the electrical aging and breakdown of polyethylene," IEEE Electrical Insulation and Dielectric Phenomena, vol. 12, no. 5, pp. 951-966, 2005. 

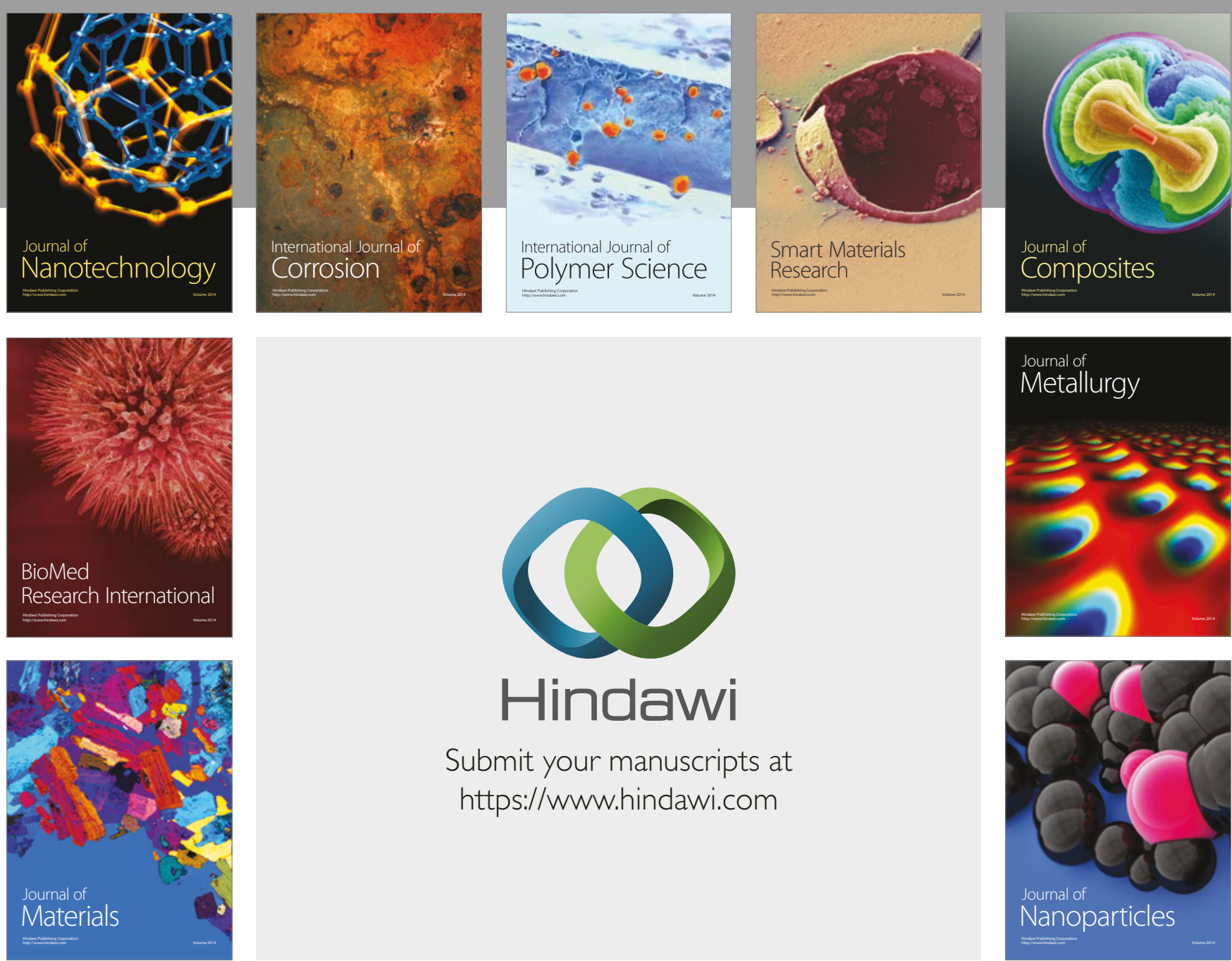

\section{Hindawi}

Submit your manuscripts at

https://www.hindawi.com
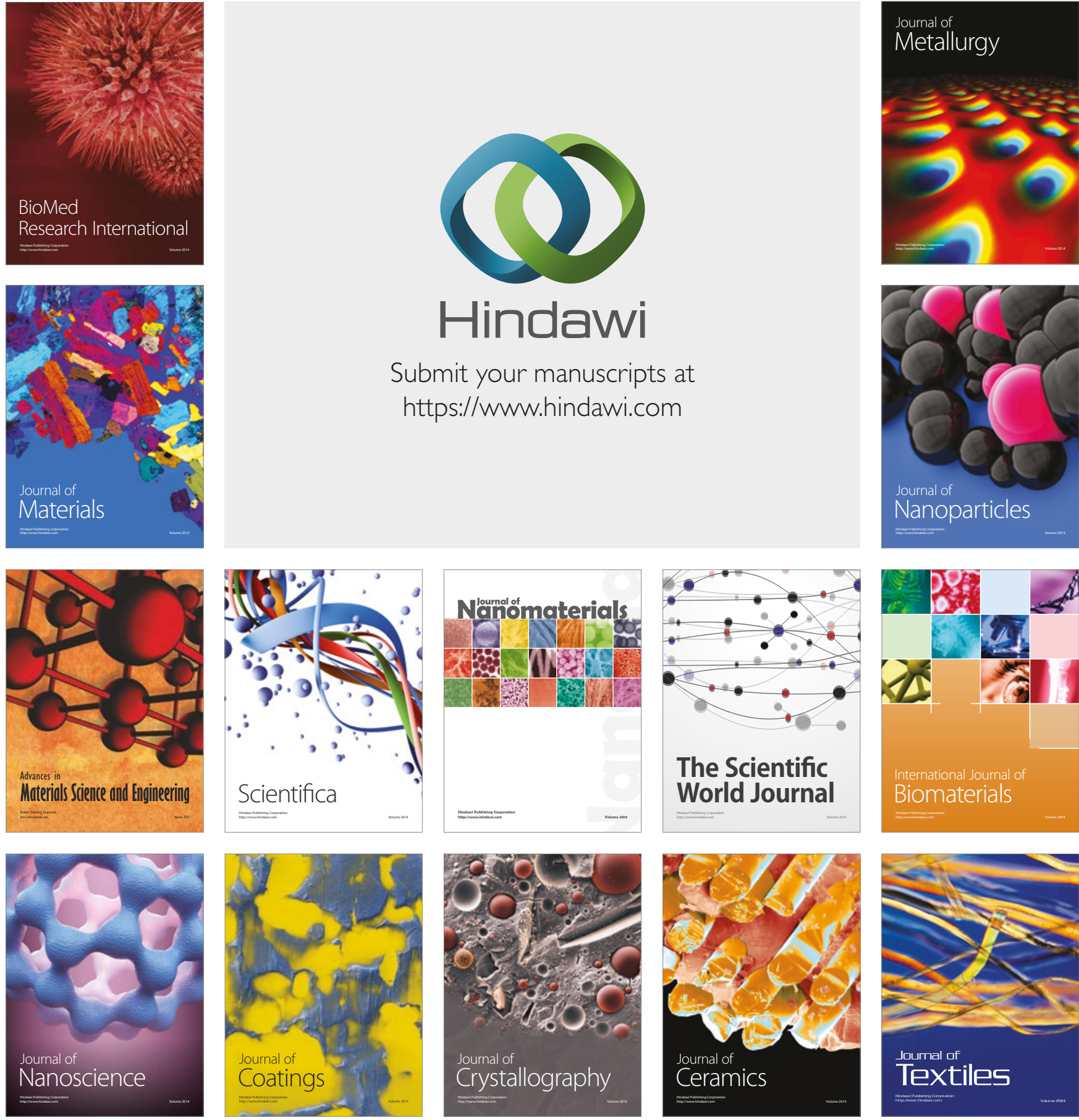

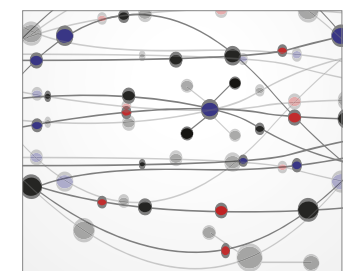

The Scientific World Journal
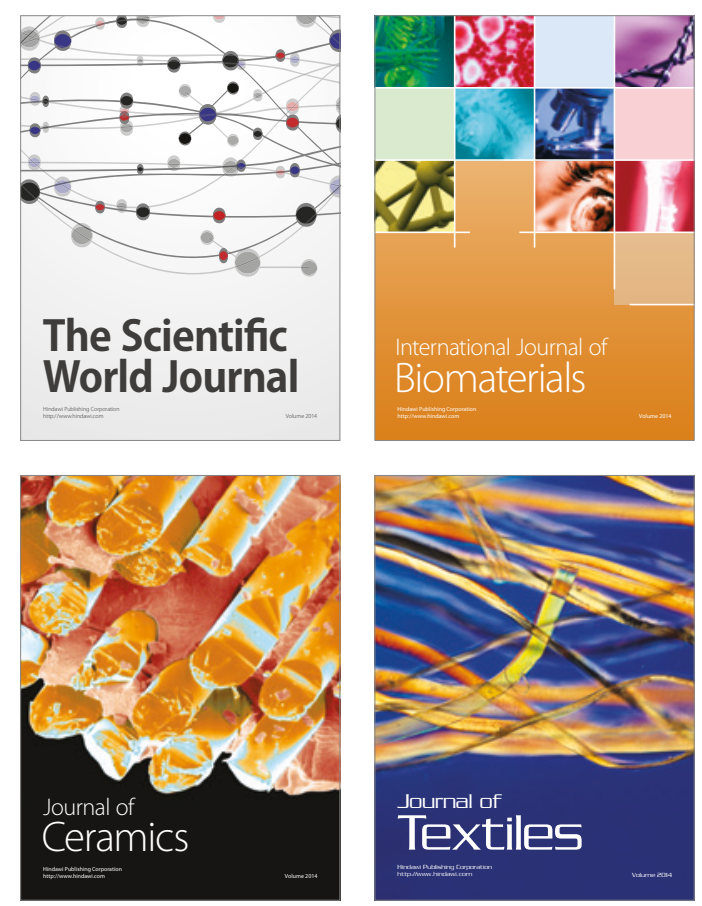